\title{
Ecological Analysis to Study Association between Prevalence of Smokeless Tobacco Type and Head-and-Neck Cancer
}

\begin{abstract}
Context: Head-and-neck cancers (HNCs) are most common cancer in Indian cancer registries. However, there is a huge variation and heterogeneity in use of different types of smokeless tobacco (SLT) consumption across India. Aims: The aims and objectives of this study were to investigate how different types of SLT use are distributed across Indian states and examined its association with different subsites of HNC incidence rates. Settings and Design: Ecological analysis of correlation between SLT prevalence and incidence rates from population-based cancer registries. Methods: Incidence data was extracted from population-based cancer registries report from the National Cancer Registry Programme database 2012-2014. The current SLT uses the prevalence of all Indian States and Union territories from Global Adult Tobacco Survey 2009-2010. Statistical Analysis Used: Pearson's correlation coefficient was used to estimate an ecological correlation between the prevalence of types of SLT uses in different region of India and age-adjusted incidence rate of different subsites of HNC. Results: In our brief analysis, we found a significant correlation between certain types of SLT use and subsite of HNC. Betel quid and tobacco use are correlated ( $r=0.53)$ with oropharynx cancer incidence. Khaini use is correlated with hypopharynx cancer incidence $(r=0.48)$. Gutka use is correlated with mouth cancer incidence $(r=0.54)$. Oral tobacco is correlated with mouth cancer incidence $(r=0.46)$. Other SLT use is correlated for hypopharynx cancer incidence $(r=0.47)$. Conclusions: The variations in SLT use across Indian states account for differences in incidence rates of HNC subsites across the states. The inferences from this brief analysis can be used as a base to modify and design observational epidemiological studies in the future.
\end{abstract}

Keywords: Ecological correlation, head-and-neck cancer, smokeless tobacco

\section{Introduction}

Head-and-neck cancers (HNCs) are most common cancer in Indian cancer registries. According to Globocan (International Agency for Research on Cancer [IARC], WHO) 2012, oral cavity cancers are second-most common cancer in Indian males and third-most common cancer in Indian females. ${ }^{[1]}$ Even after continuous efforts by the Indian Government to implement anti-tobacco measures and efforts to spread awareness about the harmful outcomes of tobacco use, HNCs are still at rise. Global Adult Tobacco Survey (GATS) 2009-2010 India reported tobacco consumption in more than one-third (35\%) of adults in India. However, there is a huge variation and heterogeneity in use of different types of smokeless tobacco (SLT) consumption across India.

This is an open access journal, and articles are distributed under the terms of the Creative Commons Attribution-NonCommercial-ShareAlike 4.0 License, which allows others to remix, tweak, and build upon the work non-commercially, as long as appropriate credit is given and the new creations are licensed under the identical terms.

For reprints contact: reprints@medknow.com
The heterogeneity in SLT consumption and its implication in $\mathrm{HNC}$ incidence pattern need to be examined to help us in a better understanding of the tobacco epidemic in India. The aims and objectives of this study were to investigate how different types of SLT use are distributed across Indian states and examined its association with different subsites of $\mathrm{HNC}$ incidence rates.

\section{Methods}

\section{Sources of data}

We used age-adjusted incidence rates (AARs) of 31 population-based cancer registries from the National Cancer Registry Programme database 2012-2014. ${ }^{[2]}$ Moreover, the current SLT use the prevalence of Indians aged $\geq 15$ years of all Indian States and Union territories from GATS 2009-2010. ${ }^{[3]}$ The SLT prevalence for Betel quid + Tobacco, Gutka (tobacco, lime, and

\footnotetext{
How to cite this article: Gholap DD, Chaturvedi P, Dikshit RP. Ecological analysis to study association between prevalence of smokeless tobacco type and head-and-neck cancer. Indian J Med Paediatr Oncol 2018;39:456-62.
}

\section{Devyani Dilip Gholap, Pankaj Chaturvedi', Rajesh Prabhakar Dikshit}

Centre for Cancer Epidemiology, Tata Memorial Centre (ACTREC Campus), Homi Bhabha National Institute, Training School Complex, Anushkatinagar, ${ }^{\prime}$ Department of Head and Neck services, Tata Memorial Hospital, Mumbai, Maharashtra, India

\section{-}

Address for correspondence:

Dr. Rajesh Prabhakar Dikshit, Room No. 202, Centre for Cancer Epidemiology Building, ACTREC Campus, Kharghar Sector 32, Mumbai, Maharashtra, India. E-mail:dixr24@hotmail.com 
areca nut mixture), Khaini (tobacco and lime mixture), Other tobacco (snuff, gul, gudakhu, and mishri) and other smokeless tobacco (OST) (betel quid without tobacco, paan masala, and nasal use of snuff) were taken for every Indian State and Union territory. The study examines following subsites of HNC - tongue (C01-C02), mouth (C03-C06), oropharynx (C10), and hypopharynx (C12-C13). The cancer sites are coded by the International Classification of Diseases for Oncology (ICD-O) code.

\section{Statistical analysis}

To estimate an ecological correlation between the prevalence of types of SLT uses in different region of India and prevalence of different types of SLT, we used Pearson's correlation coefficient. Pearson's correlation coefficient (r) was determined between AARs of HNC subsites versus current SLT prevalence in Indians aged $\geq 15$ years males and females. For states having more than one population-based cancer registry, average AAR was calculated of a particular HNC subsite by adding all the AAR and dividing them by the number $(n)$ of registries. The analysis was done separately for males and females. Statistical significance was considered at $\alpha<0.05$. All statistical analyzes were performed using STATA (version 15.0; Stata Corp, College Station, TX, USA).

\section{Results}

Table 1 represents the state-wise prevalence of smokeless products chewed and AARs corresponding to the number of incident cases of HNC subsites of males.
The prevalence of chewing $\mathrm{BQ}+\mathrm{T}$ in males is highest in Nagaland state (27.2\%) followed by Arunachal Pradesh and Assam. The prevalence of chewing Khaini in males is highest in Nagaland (34.3\%) followed by Assam and Arunachal Pradesh. The prevalence of chewing Gutka in males is highest in Madhya Pradesh (26.7\%) followed by Gujarat and Arunachal Pradesh. The prevalence of chewing/applying oral tobacco products in males is highest in Maharashtra (4.2\%) followed by Gujarat and Tamil Nadu. The prevalence of chewing other smokeless products, such as paan masala and betel quid without tobacco, in males is highest in Arunachal Pradesh (24.9\%) followed by Mizoram and Nagaland.

Similarly, AAR of tongue cancer is highest in Gujarat followed by Delhi and Meghalaya. AAR of mouth cancer is highest in Gujarat followed by Madhya Pradesh and Delhi. AAR of Oropharynx cancer is highest in Nagaland followed by Assam and Kerala. AAR of Hypopharynx cancer is highest in Nagaland followed by Meghalaya and Assam.

Table 2 represents the state-wise prevalence of smokeless products chewed and AAR corresponding to a number of incident cases of HNC subsites of females.

The prevalence of chewing $\mathrm{BQ}+\mathrm{T}$ in females is highest in Tripura state (38.9\%) followed by Meghalaya and Nagaland. The prevalence of chewing Khaini in females is highest in Mizoram (34.3\%) followed by Nagaland and Sikkim. The prevalence of chewing Gutka in females is highest in Arunachal Pradesh (11.4\%) followed by Nagaland and

\begin{tabular}{|c|c|c|c|c|c|c|c|c|c|}
\hline \multirow[t]{2}{*}{ State } & \multicolumn{5}{|c|}{ Prevalence of different smokeless products (\%) } & \multicolumn{4}{|c|}{ AAR of HNC sub-sites } \\
\hline & $\begin{array}{c}\mathbf{B Q}+ \\
\mathbf{T}^{*}\end{array}$ & Khaini & Gutka & $\begin{array}{c}\text { Oral } \\
\text { tobacco' }\end{array}$ & $\begin{array}{c}\text { Other } \\
\text { smokeless } \\
\text { products } \|\end{array}$ & $\begin{array}{c}\text { Tongue } \\
\text { (AAR/number } \\
\text { of cases) }\end{array}$ & $\begin{array}{l}\text { Mouth (AAR/ } \\
\text { number of } \\
\text { cases) }\end{array}$ & $\begin{array}{c}\text { OPX" (AAR/ } \\
\text { number of } \\
\text { cases) }\end{array}$ & $\begin{array}{c}\text { HPX" (AAR/ } \\
\text { number of } \\
\text { cases) }\end{array}$ \\
\hline Nagaland & 27.2 & 34.3 & 12 & 1.2 & 11.5 & $3.45 / 20$ & $5.38 / 34$ & $4.1 / 11$ & $15.16 / 48$ \\
\hline Tripura & 27 & 9.1 & 2.5 & 0.5 & 3.9 & $4.16 / 198$ & $4.45 / 217$ & $1.43 / 67$ & $4.43 / 207$ \\
\hline Arunachal Pradesh & 18.2 & 23.1 & 20.5 & 2.5 & 24.9 & $2.59 / 17$ & $1.80 / 18$ & $1.02 / 3$ & $4.42 / 27$ \\
\hline Assam & 17.8 & 25.7 & 10.4 & 1.5 & 10.3 & $5.83 / 305$ & $7.94 / 415$ & $2.13 / 106$ & $13.2 / 676$ \\
\hline Karnataka & 10.4 & 1.8 & 10.5 & 0.9 & 0.4 & $4.3 / 162$ & $3.92 / 148$ & $0.8 / 28$ & $3.28 / 115$ \\
\hline Sikkim & 10.2 & 17.9 & 5.9 & 1.5 & 5 & $1.78 / 14$ & $4.33 / 33$ & $0.35 / 3$ & $1.83 / 13$ \\
\hline West Bengal & 10 & 13.4 & 7.2 & 1.7 & 2.3 & $5.39 / 152$ & $6.78 / 191$ & $0.32 / 9$ & $1.97 / 53$ \\
\hline Madhya Pradesh & 9.7 & 19.7 & 26.7 & 2.1 & 7.1 & $8.43 / 156$ & $14.27 / 263$ & $0.92 / 15$ & $4.72 / 75$ \\
\hline Kerala & 8.7 & 3 & 1.6 & 1.3 & 2 & $5.8 / 625$ & $6.56 / 700$ & $2.02 / 215$ & $1.95 / 204$ \\
\hline Meghalaya & 5.5 & 7.5 & 1.1 & 0.1 & 5.4 & $9.23 / 151$ & $7.93 / 118$ & $1.8 / 29$ & $15.12 / 238$ \\
\hline Gujarat & 4.9 & 9.6 & 21.7 & 3.4 & 4.4 & $10.4 / 627$ & $18.11 / 1113$ & $0.54 / 29$ & $3.51 / 180$ \\
\hline Maharashtra & 4.5 & 22.8 & 13.4 & 4.2 & 2.2 & $4.38 / 967$ & $7.77 / 1736$ & $0.37 / 106$ & $1.48 / 380$ \\
\hline Tamil Nadu & 2.8 & 1.1 & 1.2 & 3.4 & 1.5 & $7.38 / 380$ & $8.54 / 436$ & $1.83 / 86$ & $3.5 / 162$ \\
\hline Mizoram & 2.4 & 15.1 & 2.1 & 0.8 & 18.8 & $3.64 / 49$ & $2.95 / 38$ & $0.89 / 12$ & $10.16 / 129$ \\
\hline Delhi & 2.2 & 5 & 13.2 & 0.5 & 0.7 & $9.33 / 659$ & $9.46 / 703$ & $1.77 / 112$ & $2.29 / 136$ \\
\hline Punjab & 0.9 & 6.9 & 4.9 & 0.4 & 0 & $3.48 / 185$ & $2.93 / 168$ & $0.51 / 23$ & $0.87 / 52$ \\
\hline Chandigarh & 0.5 & 5 & 3.2 & 0 & 0.3 & $4.3 / 23$ & $4.2 / 25$ & $0.5 / 5$ & $2.3 / 3$ \\
\hline
\end{tabular}

*BQ with (+) T; 'snuff,gul,gudhakhu, mishri; ||Paan masala, betel quid without tobacco and nasal use of snuff; "OPX - Oropharynx; HPX - Hypopharynx; AAR - Age-adjusted incidence rates; BQ - Betel quid; T - Tobacco, HNC - Head-and-neck cancer 


\begin{tabular}{|c|c|c|c|c|c|c|c|c|c|}
\hline \multirow[t]{2}{*}{ State } & \multicolumn{5}{|c|}{ Prevalence of different smokeless products (\%) } & \multicolumn{4}{|c|}{ AAR of HNC sub-sites } \\
\hline & $\begin{array}{c}\text { BQ + } \\
\mathbf{T}^{*}\end{array}$ & Khaini & Gutka & $\begin{array}{c}\text { Oral } \\
\text { tobacco }\end{array}$ & $\begin{array}{c}\text { Other } \\
\text { smokeless } \\
\text { products } \|\end{array}$ & $\begin{array}{c}\text { Tongue } \\
\text { (AAR/number } \\
\text { of cases) }\end{array}$ & $\begin{array}{c}\text { Mouth (AAR/ } \\
\text { number of } \\
\text { cases) }\end{array}$ & $\begin{array}{l}\text { OPX" (AAR/ } \\
\text { number of } \\
\text { cases) }\end{array}$ & $\begin{array}{c}\text { HPX" (AAR/ } \\
\text { number of } \\
\text { cases) }\end{array}$ \\
\hline Tripura & 38.9 & 2.4 & 1.8 & 0.4 & 1.7 & $1.21 / 55$ & $2.79 / 132$ & $0.2 / 9$ & $0.41 / 19$ \\
\hline Meghalaya & 23.4 & 4.2 & 1.4 & 2.6 & 8 & $2.22 / 36$ & $7.71 / 125$ & $0.26 / 4$ & $2.24 / 37$ \\
\hline Nagaland & 22.6 & 17.4 & 7.4 & 0.5 & 15.3 & $1.52 / 10$ & $1.94 / 12$ & $0 / 0$ & $6.81 / 7$ \\
\hline Mizoram & 11.7 & 34.3 & 6.2 & 5.6 & 18.1 & $0.84 / 10$ & $1.66 / 21$ & $0 / 0$ & $1.15 / 14$ \\
\hline Assam & 11.4 & 2.3 & 4.1 & 1.9 & 10.4 & $2.36 / 109$ & $4.67 / 218$ & $0.8 / 31$ & $2.53 / 120$ \\
\hline Arunachal Pradesh & 10.3 & 13 & 11.4 & 2.2 & 16.2 & $0.63 / 8$ & $1.5 / 12$ & $0.14 / 1$ & $0.2 / 2$ \\
\hline Karnataka & 9.5 & 2.9 & 1.1 & 2.9 & 3.2 & $1.17 / 42$ & $5.38 / 179$ & $0.16 / 5$ & $0.78 / 29$ \\
\hline West Bengal & 8.5 & 4.2 & 1.7 & 7.1 & 1.8 & $2.36 / 60$ & $3.01 / 77$ & $0.16 / 4$ & $0.42 / 10$ \\
\hline Tamil Nadu & 6.6 & 0 & 0.3 & 0.3 & 1.7 & $2.03 / 101$ & $3.99 / 190$ & $0.24 / 11$ & $1.52 / 78$ \\
\hline Kerala & 6.6 & 1.5 & 2.1 & 1.8 & 2.2 & $2.26 / 285$ & $3.32 / 425$ & $0.12 / 17$ & $0.17 / 23$ \\
\hline Sikkim & 4.2 & 10.9 & 6.8 & 0.2 & 7.5 & $0.48 / 4$ & $2.52 / 17$ & $0.15 / 1$ & $0.39 / 2$ \\
\hline Madhya Pradesh & 3.7 & 8 & 6.4 & 7 & 4.7 & $3.66 / 58$ & $5.51 / 85$ & $0.07 / 1$ & $0.34 / 6$ \\
\hline Maharashtra & 3.7 & 4.9 & 2.5 & 12.2 & 1.6 & $1.88 / 374$ & $2.9 / 644$ & $0.1 / 26$ & $0.55 / 117$ \\
\hline Gujarat & 1.9 & 0.3 & 0.1 & 0.7 & 0.5 & $3.39 / 188$ & $3.63 / 197$ & $0.13 / 6$ & $0.9 / 52$ \\
\hline Delhi & 0.5 & 0.8 & 1.9 & 0 & 0.1 & $2.98 / 193$ & $3.26 / 213$ & $0.19 / 13$ & $0.48 / 29$ \\
\hline Chandigarh & 0.5 & 0.1 & 0.5 & 0.2 & 0.1 & $1.8 / 9$ & $0.4 / 4$ & $0 / 0$ & $0.4 / 2$ \\
\hline Punjab & 0 & 0.1 & 0.1 & 0 & 0 & $0.85 / 49$ & $0.87 / 48$ & $0.21 / 4$ & $0.3 / 17$ \\
\hline
\end{tabular}

*BQ with (+) T; 'snuff,gul,gudhakhu, mishri; ||Paan masala, betel quid without tobacco and nasal use of snuff; "OPX - Oropharynx; HPX - Hypopharynx; AAR - Age-adjusted incidence rates; BQ - Betel quid; T - Tobacco, HNC - Head-and-neck cancer

Sikkim. The prevalence of chewing/applying oral tobacco products in females is highest in Maharashtra $(12.2 \%)$ followed by West Bengal and Mizoram. The prevalence of chewing other smokeless products, such as paan masala and betel quid without tobacco, in females is highest in Mizoram (18.1\%) followed by Arunachal Pradesh and Nagaland.

Similarly, AAR of tongue cancer is highest in Madhya Pradesh followed by Gujarat and Delhi. AAR of mouth cancer is highest in Meghalaya followed by Madhya Pradesh and Karnataka. AAR of Oropharynx cancer is highest in Assam followed by Tamil Nadu and Punjab. AAR of Hypopharynx cancer is highest in Nagaland followed by Assam and Meghalaya.

Graph 1 represents the scatter plots of $\mathrm{BQ}+\mathrm{T}$ versus HNC subsites for both males and females. Betel quid and tobacco use $(\mathrm{BQ}+\mathrm{T})$ is significantly correlated $(r=0.53)$ with oropharynx cancer for males. BQ $+\mathrm{T}$ use also showed nonsignificant correlation for males and females $(r=0.40 ; r=0.40)$ with hypopharynx cancer. $\mathrm{BQ}+\mathrm{T}$ use was negatively correlated with tongue cancer incidence in males and females $(r=0.33 ; r=-0.24)$. The correlation was nonsignificant. BQ $+\mathrm{T}$ use showed nonsignificant correlation with mouth cancer in females $(r=0.21)$, whereas it was negatively correlated in males $(r=0.21)$.

Graph 2 represents the scatter plots of Khaini versus HNC subsites for both males and females. Khaini use was nonsignificantly correlated $(r=0.32)$ with oropharynx cancer in males. It was also correlated with hypopharynx cancer for males and females $(r=0.48 ; r=0.29)$. It was negatively correlated with tongue (males $r=-0.41$ and females $r=-0.34$ ) and mouth cancer (males $r=-0.03$ and females $r=-0.25$ ) in both genders.

Graph 3 represents the scatter plots of Gutka versus HNC subsites for both males and females. Gutka use was significantly correlated with mouth cancer incidence in males $(r=0.54)$ but negatively correlated in females $(r=-0.19)$. Gutka use showed nonsignificant correlation with tongue cancer in males $(r=0.26)$ and negative correlation in females $(r=-0.33)$. Gutka use showed a positive correlation with hypopharynx cancer incidence in females $(r=0.23)$.

Graph 4 represents the scatter plots of oral tobacco versus HNC subsites for both males and females. Oral tobacco use was nonsignificantly correlated with mouth cancer incidence in males $(r=0.46)$ and slight correlation in females $(r=0.17)$. It shows slight positive correlation for tongue cancer in both genders (males $r=0.14$ and females $r=0.17)$.

Oral tobacco use was negatively correlated for oropharynx and hypopharynx incidence rates in both genders.

Graph 5 represents the scatter plots of OST versus HNC subsites for both males and females. OST use was correlated for hypopharynx cancer incidence in both genders (males $r=0.47$; females $r=0.49$ ), the correlation 


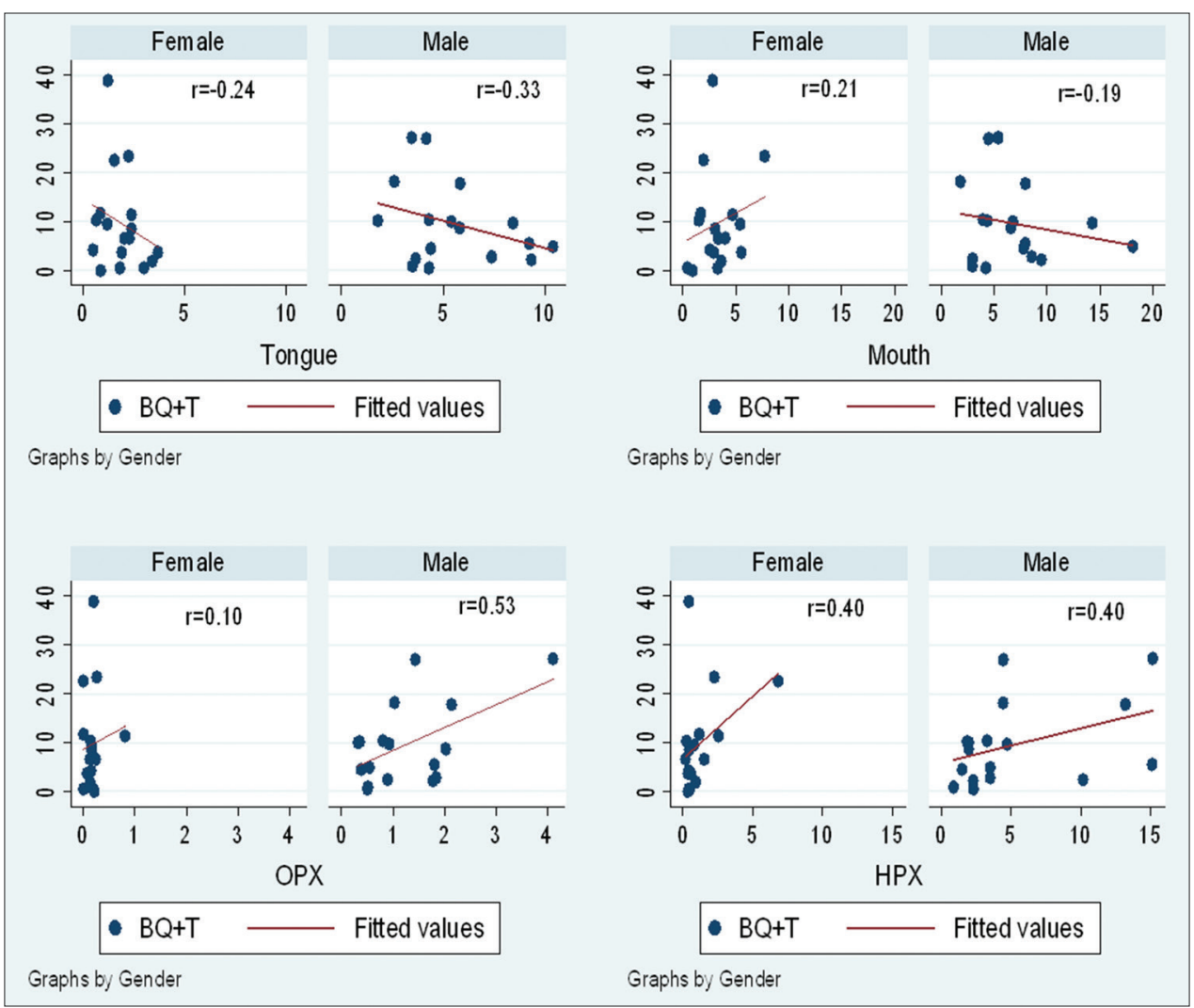

Graph 1: $B Q+T$ versus head-and-neck cancer subsites

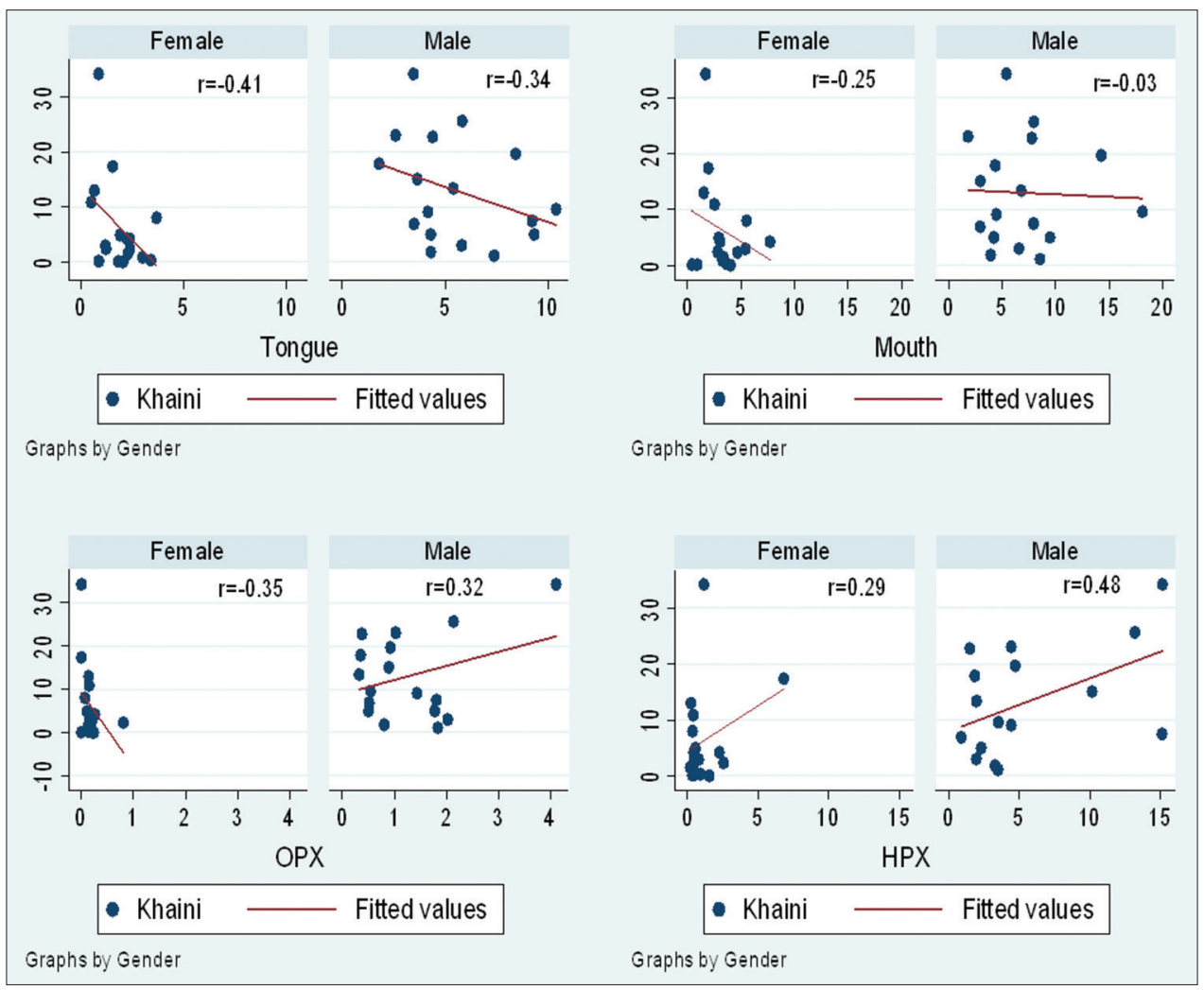

Graph 2: Khaini versus head-and-neck cancer subsites

in females was significant. OST use was slightly correlated OST use showed no correlation with oropharynx cancer with oropharynx cancer incidence in males $(r=0.19)$. incidence in females. 


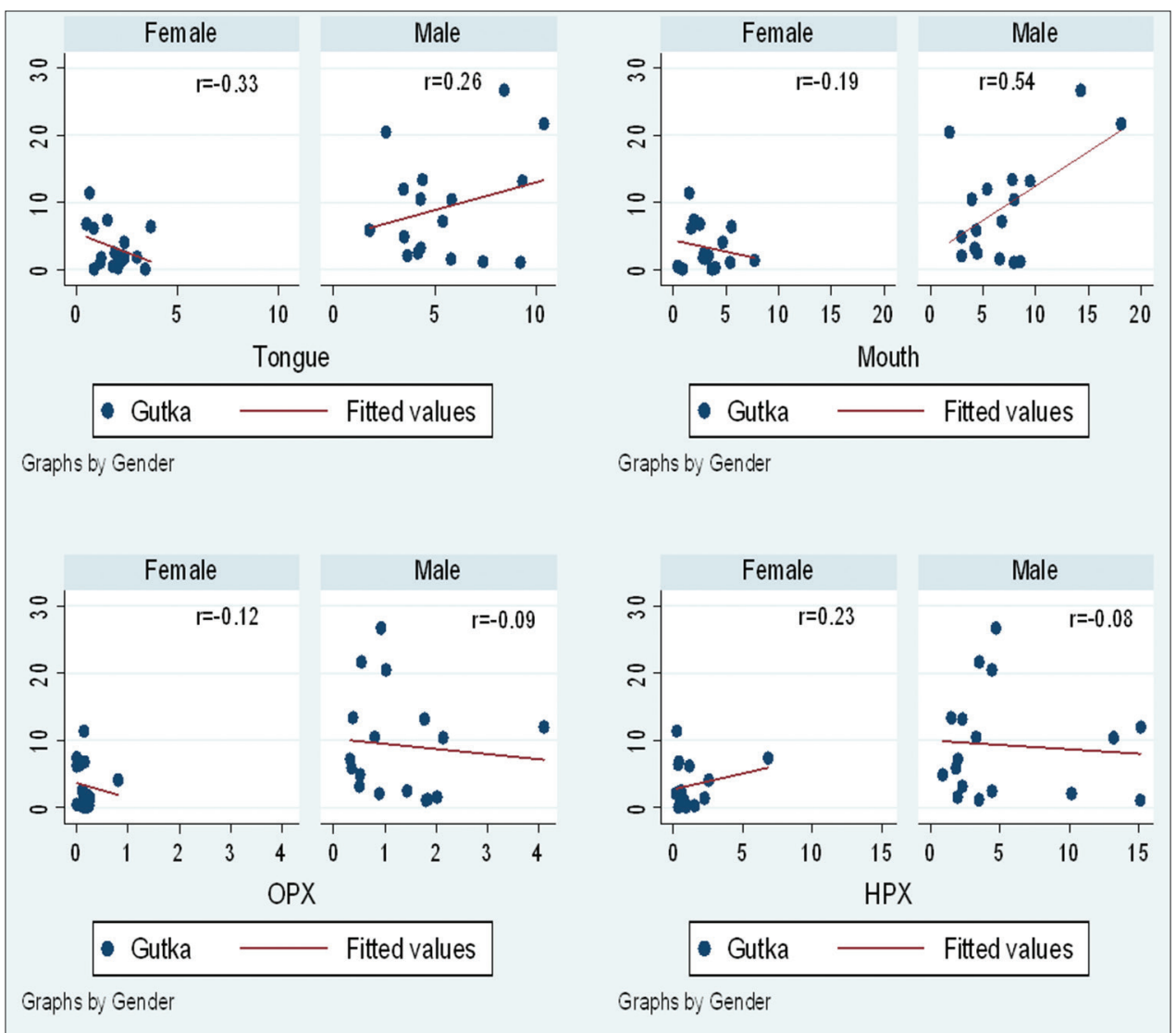

Graph 3: Gutka versus head-and-neck cancer subsites

OST use was negatively correlated for incidence rates of tongue and mouth cancers in both genders.

\section{Discussion}

The objective of this analysis was to describe state-specific incidence rates of $\mathrm{HNC}$ subsites and to examine the correlation between state-specific prevalence of SLT use and $\mathrm{HNC}$ incidence rates among Indians aged $\geq 15$ years males and females. India is a large country with each state having its own set of sociocultural variations. This also accounts for huge heterogeneity in SLT use across all states. According to GATS 2009-2010 report, 20.6\% of Indian adults aged $\geq 15$ years reported current use of SLT only and $8.7 \%$ of adults reported use of smoked tobacco only. ${ }^{[3]}$ Therefore, oral and pharyngeal cancer burden in India should be attributed more to use SLT.

There are geographical variations within subsites of head and neck. In some states, both tongue and mouth cancers rates are high, while in some states, only mouth cancer rates are higher (Madhya Pradesh, Tamil Nadu, and Delhi). The cancer rates for both mouth and tongue are low; possibly because of the low prevalence of SLT use due to religious constraints. The oropharynx and hypopharynx rates are low and almost similar in all the states of India, possibly indicating that they are not affected by types of SLT.
In our brief analysis, we found a strong correlation between BQ $+T$ use and incidence rates of oropharynx and hypopharynx cancers. This may be due to the practice of swallowing the chewed/sucked quid. Swallowing leads to exposure of oropharynx and hypopharynx subsites to the carcinogens. Gutka use was strongly correlated to mouth and tongue cancer incidence rates. Oral tobacco use data collected in GATS survey includes use of snuff and products used for application or dentifrice such as gul, gudakhu, and mishri. Its use was strongly correlated to mouth and tongue cancer incidence rates, which justifies as the use of these products are mainly for application. Tongue and mouth regions are primarily exposed to the carcinogens. OST data collected in GATS survey includes the use of paan masala, betel quid without tobacco, and nasal use of snuff. Its use was strongly correlated to incidence of hypopharynx cancer. Paan masala and betel quid without tobacco largely contain areca nut. A case-series study conducted by Muttagi et al. in 2012 identified areca nut as an independent risk factor for hypopharynx cancer. ${ }^{[4]}$ However, little importance is given to areca nut control and spreading awareness about harmful effects of its consumption in cancer control campaigns. In our study, we found that there are variations in SLT use across Indian states. These variations account for differences in incidence rates of HNC subsites across the states. However, tobacco control programs in India do not focus on these differences and give out a generic message to the masses. Therefore, we feel and opine that there 


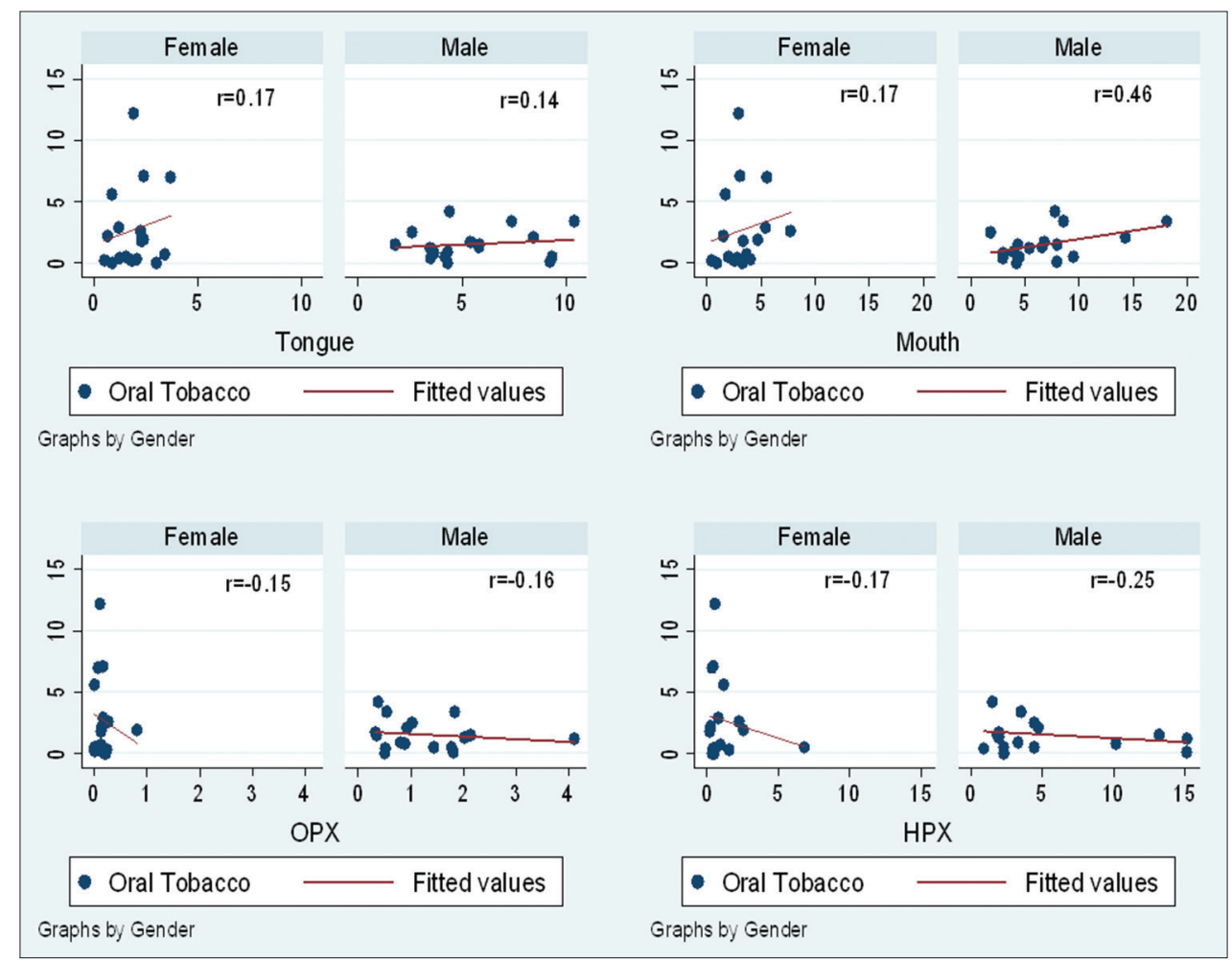

Graph 4: Oral tobacco versus head-and-neck cancer subsites

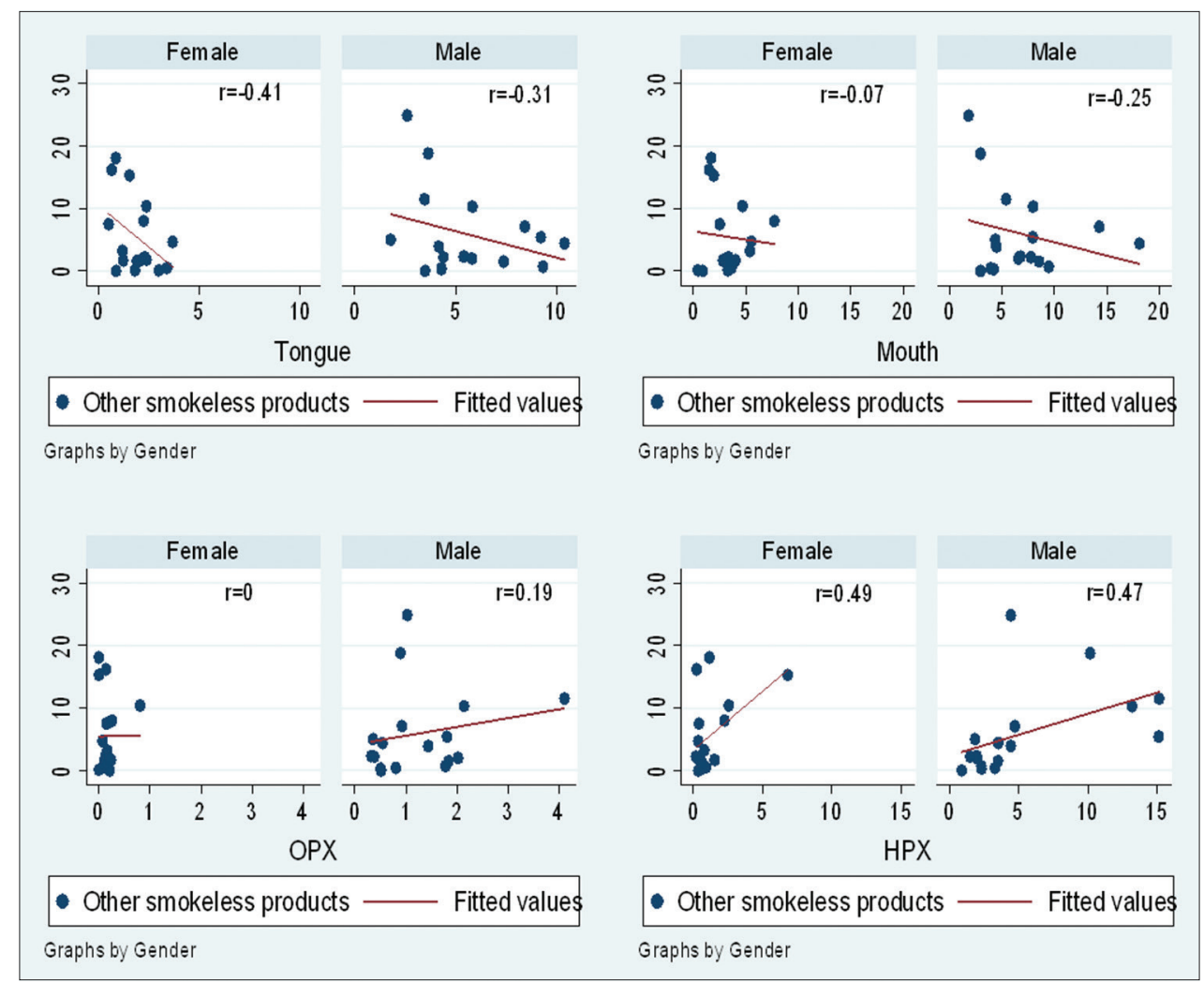

Graph 5: Other smokeless tobacco versus head-and-neck cancer subsites

should be targeted state or region-specific tobacco control policies which take into account these inequalities in SLT and $\mathrm{HNC}$ cancer incidence rates.
SLT products in India range in complexity to tobacco only and contain numerous additives and chemical ingredients. ${ }^{[5]}$ Carcinogenic compounds in SLT include 
polycyclic aromatic hydrocarbons, lactones, coumarin, ethyl carbamate, some volatile aldehydes, volatile $\mathrm{N}$-nitrosamines, nitrosamino acids, tobacco-specific N-nitrosamines (TSNA), inorganic compounds, radioactive Polonium 210, and Uranium 235 and 238. N-Nitrosonornicotine (NNN), 4-(methylnitrosamino)1-(3-pyridyl)-1-butanone (NNK), and N-nitrosamino acids are quantitatively the most prevalent strong carcinogens in SLT. ${ }^{[5]}$ Both NNN and NNK have been reported as Class 1 carcinogens to humans by IARC. In a study by Stepanov et al., high levels of NNK, NNN, NAB, and NAT were reported in zarda and khaini, and TSNA level in gutka was higher than the permissible limits in food. ${ }^{[6]}$ Owing to the complexity and variety of chemical ingredients contained in SLT products marketed in India, there should a uniform national database of chemical compositions and carcinogens of each form of SLT. This will help to strengthen the anti-tobacco campaigns and help to understand the tobacco epidemic in India.

\section{Conclusions}

The variations in SLT use across Indian states account for differences in incidence rates of HNC sub-sites across the states. The inferences from this brief analysis can be used as a base to modify and design observational epidemiological studies in the future.

\section{Limitations of the study}

We did not take into account (or adjust) tobacco smoking prevalence in our study as our primary objective was to study the differences in incidence rates in relation to SLT use. The SLT prevalence in GATS study is based on self-report, and hence, there are no measures of validation taken. The tobacco prevalence data were self-reported for current use of SLT. We drew casual inferences from cross-sectional survey data.

Financial support and sponsorship

Nil.

\section{Conflicts of interest}

There are no conflicts of interest.

\section{References}

1. Ferlay J, Soerjomataram I, Ervik M, Dikshit R, Eser S, Mathers C. GLOBOCAN 2012 v1.0, Cancer Incidence and Mortality Worldwide: IARC Cancer Base No. 11. Lyon, France: International Agency for Research on Cancer; 2013, 2018. Available from: http://www.globocan.iarc.fr. [Last accessed on 2016 Apr 26].

2. Three Year Population Report of Population based Cancer Registries 2012-14. National Centre for Disease Informatics and Research-National Cancer Registry Programme (ICMR), Bangalore; 2018. Available from: Available from: http:// www.ncdirindia.org/NCRP/ALL_NCRP_REPORTS/ PBCR_REPORT_2012_2014/index.htm. [Last accessed on 2016 Apr 26].

3. Global Adult Tobacco Survey. India, Report, 2009-2010. Ministry of Health and Family Welfare, Government of India; 2018. Available from: http://www.who.int/tobacco/surveillance/ survey/gats/ind/en/. [Last accessed on 2016 Apr 26].

4. Muttagi SS, Chaturvedi P, Gaikwad R, Singh B, Pawar P. Head and neck squamous cell carcinoma in chronic areca nut chewing Indian women: Case series and review of literature. Indian J Med Paediatr Oncol 2012;33:32-5.

5. Bhisey RA. Chemistry and toxicology of smokeless tobacco. Indian J Cancer 2012;49:364-72.

6. Stepanov I, Hecht SS, Ramakrishnan S, Gupta PC. Tobacco-specific nitrosamines in smokeless tobacco products marketed in India. Int J Cancer 2005;116:16-9. 